J. Lake Sci.(湖泊科学), 2008, 20(3): 334-338

http://www.jlakes.org. E-mail: jlakes@niglas.ac.cn

(C)2008 by Journal of Lake Sciences

\title{
鄱阳湖区水体氮、磷污染状况分析*
}

\author{
王毛兰 ${ }^{1,2}$, 周文斌 ${ }^{1,2}$, 胡春华 ${ }^{1,2}$ \\ (1: 南昌大学鄱阳湖湖泊生态与生物资源利用教育部重点实验室, 南昌 330047) \\ (2: 南昌大学环境科学与工程学院, 南昌 330031)
}

摘 要: 通过系统测定鄱阳湖湖水、主要人湖口河水及部分农田水、地下水及城市污水氮磷含量, 对其氮、磷污染状况进行 了分析，同时对湖水及河水的氮、磷来源进行了初步讨论. 结果表明，鄱阳湖区水体已达到一定程度的氮、磷污染，特别是饶 河段氮含量较高 $(0.89-3.15 \mathrm{mg} / \mathrm{L})$, 信江磷含量较高 $(0.098-0.22 \mathrm{mg} / \mathrm{L})$, 而湖体的总氮、总磷含量也分别达到 $1.06 \pm 0.28 \mathrm{mg} / \mathrm{L}$ 和 $0.067 \pm 0.042 \mathrm{mg} / \mathrm{L}$ ，已具备富营养化的条件.

关键词: 氮; 磷; 富营养化; 鄱阳湖区

\section{Status of nitrogen and phosphorus in waters of Lake Poyang Basin}

\author{
WANG Maolan ${ }^{1,2}$, ZHOU Wenbin ${ }^{1,2} \&$ HU Chunhua ${ }^{1,2}$ \\ (1: Key Laboratory of Lake Poyang Ecology and Bio-resource Utilization, Ministry of Education, Nanchang University, Nanchang \\ 330047, P.R.China) \\ (2: Institute of Environmental Science and Engineering, Nanchang University, Nanchang 330031, P.R.China)
}

\begin{abstract}
Based on the systematic measurment of nitrogen $(\mathrm{N})$ and phosphorus $(\mathrm{P})$ concentrations in lake water, the main river water, partial agricultural drainage, groundwater and urban sewage, we analyzed the present situations of $\mathrm{N}$ and $\mathrm{P}$ pollution at the Lake Poyang Basin, and discussed the sources of the pollution primarily. Lake Poyang Basin was polluted by N and P at some extent, while especially Rao River was polluted by N seriously and Xin River was polluted by P badly. The concentrations of total nitrogen and total phosphorus were $1.06 \pm 0.28 \mathrm{mg} / \mathrm{L}$ and $0.067 \pm 0.042 \mathrm{mg} / \mathrm{L}$ respectively in the Lake Poyang water and the lake has subjected to eutrophication status.
\end{abstract}

Keywords: Nitrogen; phosphorus; eutrophication; Lake Poyang Basin

长江中下游许多湖泊水体富营养化非常严重 ${ }^{[1-4]}$, 而作为其中下游浅水湖泊之一的鄱阳湖水体富营 养化程度相对较低 ${ }^{[5]}$. 1988 年朱海虹等 ${ }^{[6]}$ 的研究结果显示鄱阳湖水体 TP 和 TN 含量平均值分别为 $0.076 \mathrm{mg} / \mathrm{L}$ 和 $0.684 \mathrm{mg} / \mathrm{L}$, 而李博之 ${ }^{[5]}$ 调查表明 1996 年鄱阳湖水体 TP 和 TN 含量最高值分别达到 0.148 和 $2.38 \mathrm{mg} / \mathrm{L}$. 可见，随着鄱阳湖流域经济的快速发展，鄱阳湖水体中 $\mathrm{N} 、 \mathrm{P}$ 含量在不断增加. 吕兰军 ${ }^{[7-8]}$ 的研究表明，鄱阳湖水域早在 20 世纪 90 年代初就已面临富营养化的危险，全湖有半年的时间处于富营 养化状态. 2000 年 4-9 月份鄱阳湖水体富营养化评价值为 40, 富营养化程度增加, 表明鄱阳湖正缓慢地 向富营养化趋势发展. 虽然鄱阳湖氮磷污染问题已引起人们的关注，但较为系统的研究报告极少. 本文 对鄱阳湖区水体的氮、磷分布特征进行了系统研究，为鄱阳湖水体富营养化的预防控制提供理论依据.

\section{1 研究方法}

\section{1 水样的采集}

于 2005 年 8 月 18 日至 23 日对鄱阳湖湖水及其主要支流下游的地表水进行系统采集. 同时主要采集

* 国家自然科学基金项目(40672159)及江西省教育厅科学技术研究项目(贑教技字[2005]05 号)联合资助. 2007-03-26 收稿; 2007-07-23 收修改稿. 王毛兰, 女, 1979 年生, 博士; E-mail: mlwang@ncu.edu.cn. 
了德安县和修水县排污口排出的城市生活污水; 于部 分河流采样点处采集了相对应的地下水(图 1). 地下 水通过压水井压出, 在采集前先将滞留在水管中的水 压掉, 所采集的地下水水深约为 $10 \mathrm{~m}$ 左右. 在部分河 流采样点处采集了相对应的水田里的水, 采样时正值 双抢季节, 早稻刚割, 晚稻刚栽.

河水和湖水地表水的采样深度为水面 $0.5 \mathrm{~m}$ 以下, 底层水用专门的深水采样器采集距湖底上约 $1 \mathrm{~m}$ 的水 样. 采样时, 鄱阳湖主湖区水深约为 $10 \mathrm{~m}$, 主航道水 深约 $15 \mathrm{~m}$. 五大支流赣江、抚河、修水、信江、饶河 人湖水量所占百分比分别为 $55 \% 、 12.1 \% 、 9.2 \%$ 、 $14.4 \% 、 9.3 \%$.

\section{2 测点布设方法及样品分析方法}

鄱阳湖具有 “高水是湖, 低水似河” 的独特的地 理特征, 每年汛期, 五河洪水人湖而上涨、漫滩, 湖面 扩大, 洪水一片; 冬春季节, 湖水落槽, 滩地显露, 水 面缩小. 受河水的冲刷, 主河道两边泥沙堆积, 使得 在湖中心区的左下方形成一个相对封闭的水区(滞留 区)，此区的水体交换速度相对较缓慢.

鄱阳湖采样点分布(图 1): 在流人鄱阳湖各支流的 人湖口处设置一个采样点, 以监测河流人湖口水质, 同 时在河流人湖口上游处布设一至两个采样点, 以获得

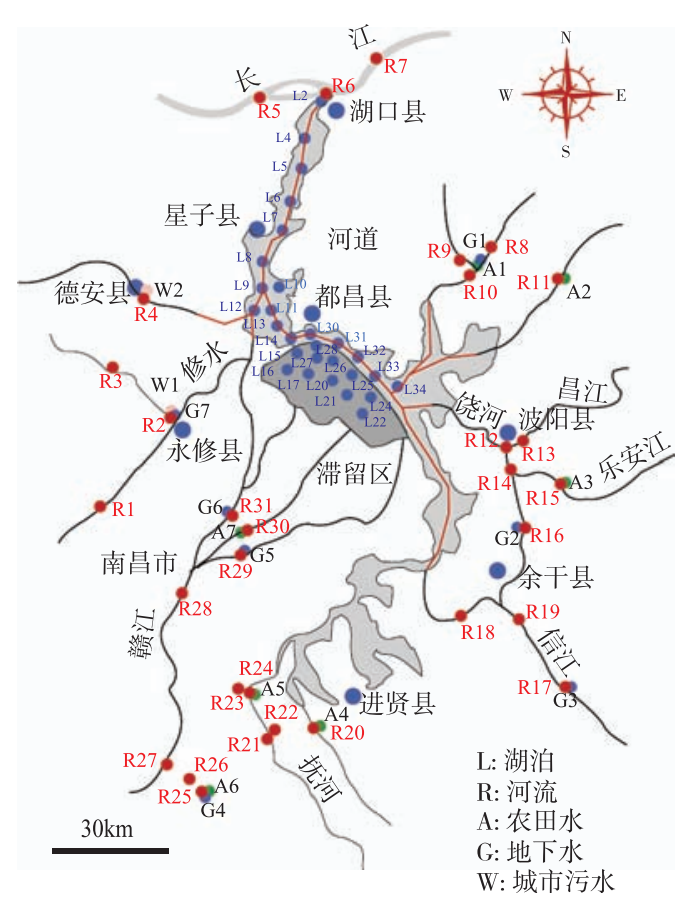

图 1 鄱阳湖采样点位置 各河流水质参数. 鄱阳湖湖体主河道沿水流方向每隔约 $10 \mathrm{~km}$ 布设一个采样点, 主湖区湖面比较宽阔(即图 中的滞留区), 因此在主湖区也布设了相应的采样点, 同时在主湖区的采样点处采集了表、底层水.

水样采集后现场用 $0.45 \mu \mathrm{m}$ 的 Millipore 滤膜过滤, 并向水样中加 $\mathrm{H}_{2} \mathrm{SO}_{4}$ 酸化保存, 立即于实验室进行 分析测定. $\mathrm{NO}_{3}{ }^{-} \mathrm{-N}$ 采用 《水和废水监测分析方法》的紫外分光光度法测定 ${ }^{[9]}$, 水样经絮凝共沉淀和吸附分 离后, 加人盐酸和氨基磺酸分别于 $220 \mathrm{~nm}$ 和 $275 \mathrm{~nm}$ 波长处测其吸光度; $\mathrm{NH}_{4}{ }^{+}-\mathrm{N}$ 使用纳氏试剂比色法 (GB/T 7479-1987)测定, 所有水样测定前加人一定量的 $\mathrm{ZnSO}_{4}$ 溶液, 用 $\mathrm{NaOH}$ 和 $\mathrm{H}_{2} \mathrm{SO}_{4}$ 溶液调 $\mathrm{pH}$ 值至 10.5, 絮凝沉淀, 静置过夜, 过滤后取滤液测定; TN 采用改进的碱性过硫酸钾消解紫外分光光度法测定 ${ }^{[10]}$, 于 水样中加人纯化过的碱性过硫酸钾, 在 $126-127^{\circ} \mathrm{C}$ 下加热 $50 \mathrm{~min}$, 自然冷却后以无氨水做参比, 在 $220 \mathrm{~nm}$ 和 $275 \mathrm{~nm}$ 处测其吸光度; TP 含量采用过硫酸钾消解锄酸铵分光光度法进行测定 ${ }^{[9]}$, 水样中加人过硫酸钾 在 $120^{\circ} \mathrm{C}$ 下加热 $30 \mathrm{~min}$, 自然冷却后加人抗坏血酸和钼酸铵于 $700 \mathrm{~nm}$ 波长处测其吸光度, 如水样中色度影 响吸光度测定时需进行色度补偿.

\section{2 结果与讨论}

\section{1 鄱阳湖入湖口河水的氮、磷污染现状}

根据已有文献报道, 当水体氮磷营养盐浓度分别达到: 无机氮 $\left(\mathrm{NH}_{4}{ }^{+}+\mathrm{NO}_{3}{ }^{-}\right) \mathrm{N} 0.2 \mathrm{mg} / \mathrm{L}$ 和无机磷 $\left(\mathrm{PO}_{4}{ }^{3-}\right)$ P $0.015 \mathrm{mg} / \mathrm{L}$ ，在其他条件具备时，就会出现水体富营养化的特征——“澡华” 现象. 表 1 结果表明，鄱阳 湖流域主要河流无机氮 $\left(\mathrm{NH}_{4}{ }^{+}-\mathrm{N}+\mathrm{NO}_{3}{ }^{-}-\mathrm{N}\right)$ 的平均浓度已达 $1.06 \mathrm{mg} / \mathrm{L}$, 总氮浓度已达 $1.28 \mathrm{mg} / \mathrm{L}$, 可见鄱阳 湖流域主要河流人湖口河水已达到一定程度的氮污染. 饶河段氮含量 $(0.89-3.15 \mathrm{mg} / \mathrm{L})$ 明显比其它河流高 出许多, 这与鄱阳县发达的渔业有关, 据统计, 2005 年鄱阳县渔业生产总值高达 87670 万元 ${ }^{[1]}$, 鱼虾的养 殖将含有大量悬浮物质和营养盐的水排入河流中, 致使河水氮含量明显偏高. 西河其氮含量也较高 $(0.78-2.06 \mathrm{mg} / \mathrm{L})$. 而信江受其上游处上饶市朝阳磷矿 (华东第一大磷矿)的影响 TP 含量偏高 $(0.098-0.22 \mathrm{mg} / \mathrm{L})$, 相关资料显示 ${ }^{[12]}$, 朝阳磷矿具有年产 $10-15$ 万吨过磷酸钙的生产能力, 磷矿生产废水的直接排放是信江 
下游 TP 含量偏高的主要原因.

表 1 鄱阳湖流域不同河流人湖口水体的氮磷值

Tab.1 Concentrations of nitrogen and phosphorus in different rivers of Lake Poyang basin

\begin{tabular}{|c|c|c|c|c|c|c|}
\hline 河流 & 采样地点 & 编号 & $\mathrm{NO}_{3}{ }^{-}-\mathrm{N}(\mathrm{mg} / \mathrm{L})$ & $\mathrm{NH}_{4}^{+}-\mathrm{N}$ & $\mathrm{TN}(\mathrm{mg} / \mathrm{L})$ & $\mathrm{TP}(\mathrm{mg} / \mathrm{L})$ \\
\hline \multirow[t]{8}{*}{ 赣江 } & 丰城市篵塘乡 & R25 & 0.99 & 0.04 & 1.33 & $*$ \\
\hline & 丰城小港镇上港村 & $\mathrm{R} 26$ & 0.46 & 0.05 & 0.84 & * \\
\hline & 小港镇 & $\mathrm{R} 27$ & 0.67 & $*$ & 1.04 & * \\
\hline & 南昌大桥 & R28 & 0.81 & * & 1.10 & * \\
\hline & 豫章大桥 & R29 & 0.96 & * & 1.17 & $*$ \\
\hline & 蒋巷 & $\mathrm{R} 30$ & 1.11 & $*$ & 1.17 & * \\
\hline & 赣江大桥 & $\mathrm{R} 31$ & 0.96 & 0.13 & 1.19 & * \\
\hline & 银河西路大桥 & $\mathrm{R} 24$ & 0.62 & 0.12 & 1.11 & * \\
\hline \multirow[t]{4}{*}{ 抚河 } & 进贤张公镇 & $\mathrm{R} 20$ & 0.38 & 0.18 & 0.65 & $*$ \\
\hline & 温圳 & $\mathrm{R} 21$ & 0.35 & 0.13 & 0.55 & * \\
\hline & 东赣渠西支 & $\mathrm{R} 22$ & 0.66 & 0.25 & 1.25 & * \\
\hline & 向塘东沙谭桥 & $\mathrm{R} 23$ & 0.56 & 0.22 & 1.44 & * \\
\hline \multirow[t]{3}{*}{ 修水 } & 安义万埠大桥 & $\mathrm{R} 1$ & 0.76 & 0.16 & 1.10 & 0.038 \\
\hline & 永修涂家埠 & $\mathrm{R} 2$ & 1.03 & 0.05 & 1.45 & 0.026 \\
\hline & 虬津大桥 & $\mathrm{R} 3$ & 0.69 & $*$ & 1.00 & $*$ \\
\hline \multirow[t]{4}{*}{ 饶河 } & 饶河 (虾场) & $\mathrm{R} 12$ & 1.09 & 1.77 & 3.15 & $*$ \\
\hline & 义昌村 & $\mathrm{R} 13$ & 0.42 & 0.29 & 0.89 & * \\
\hline & 乐安江鱼堤 & $\mathrm{R} 14$ & 1.10 & 1.30 & 2.90 & * \\
\hline & 饶丰渡口 & $\mathrm{R} 15$ & 0.71 & 0.97 & 1.81 & * \\
\hline \multirow[t]{4}{*}{ 信江 } & 余干县汪家沟 & R16 & 0.51 & 0.19 & 0.79 & 0.220 \\
\hline & 梅港水文站 & $\mathrm{R} 17$ & 0.46 & 0.16 & 0.69 & 0.098 \\
\hline & 信江西支 & $\mathrm{R} 18$ & 0.51 & 0.16 & 0.75 & 0.182 \\
\hline & 大溪渡口 & R19 & 0.34 & 0.27 & 0.67 & 0.154 \\
\hline \multirow[t]{4}{*}{ 西河 } & 鄱阳县桥头镇 & $\mathrm{R} 8$ & 0.73 & 0.36 & 1.51 & 0.015 \\
\hline & 西河西支 & R9 & 1.64 & 0.21 & 2.05 & $*$ \\
\hline & 港头村 & R10 & 1.44 & 0.46 & 2.06 & * \\
\hline & 马尾港 (碧山) & $\mathrm{R} 11$ & 0.69 & 0.08 & 0.78 & $\star$ \\
\hline 博阳河 & 德安北门大桥 & $\mathrm{R} 4$ & 1.19 & 0.19 & 1.39 & 0.030 \\
\hline 均值 & & & $0.78 \pm 0.33$ & $0.28 \pm 0.41$ & $1.28 \pm 0.63$ & $0.027 \pm 0.060$ \\
\hline
\end{tabular}

*表示低于检测限.

\section{2 鄱阳湖水体的氮、磷特征}

鄱阳湖水体无机氮的平均浓度为 $0.92 \mathrm{mg} / \mathrm{L}$, 总氮浓度为 $1.06 \mathrm{mg} / \mathrm{L}$, 比其人湖河流河水的浓度稍低些， $\mathrm{TP}$ 的含量达到 $0.067 \mathrm{mg} / \mathrm{L}$, 明显高于人湖口河水 $\mathrm{TP}$ 的含量 (表 2). 湖泊底泥磷的释放是引起鄱阳湖磷含 量高的主要原因. 夏季鄱阳湖风浪大, 风浪及采砂产生的动力作用将扰动湖底底泥, 使沉降在湖底的浮 游植物悬浮起来, 同时也将沉积物中的可溶性磷(SRP)释放出来 ${ }^{[13]}$. 近年来鄱阳湖采砂风盛行, 鄱阳湖采 砂船、运砂船只已由当初的几百条发展到了目前 160 多条功率强大的 “吸砂王”、几千条来回奔波的运输 船以及无法统计的小型挖砂船，据当地人介绍，“吸砂王”一次作业可在水底吸出一个 $60 \mathrm{~m}$ 宽的大坑，功 率大的可将水底 $30 \mathrm{~m}$ 深、 $100 \mathrm{~m}$ 范围内的砂石吸个精光.

不同湖区水体的氮含量有所不同, 主河道下游处(L2-L11)其 $\mathrm{NO}_{3}{ }^{-}-\mathrm{N}$ 浓度为 $0.60-1.29 \mathrm{mg} / \mathrm{L}$, 平均为 $0.74 \mathrm{mg} / \mathrm{L}$, 其中都昌至老爷庙段 (L8-L11)相对较高, 为 $1.05-1.29 \mathrm{mg} / \mathrm{L}$, 此处含量比其它地方高的现象与 1983-1988 年期间研究得出的结果一致 ${ }^{[14]}$, 赣江的输人是其含量高的主要原因; 而氨氮只在两处(L8, L9)被 
检测到. 中间滞留区 $(\mathrm{L} 15-\mathrm{L} 28) \mathrm{NO}_{3}{ }^{-}-\mathrm{N}$ 浓度为 $0.68-1.05 \mathrm{mg} / \mathrm{L}$, 平均为 $0.90 \mathrm{mg} / \mathrm{L} ; \mathrm{NH}_{4}{ }^{+}-\mathrm{N}$ 浓度为 $0-0.26 \mathrm{mg} / \mathrm{L}$, 平均浓度为 $0.08 \mathrm{mg} / \mathrm{L}$. 河道上游 $(\mathrm{L} 30-\mathrm{L} 34) \mathrm{NO}_{3}{ }^{-}-\mathrm{N}$ 浓度明显偏低 $(0.33-0.46 \mathrm{mg} / \mathrm{L})$, 中间滞留区氮含量高于上 游主河道, 因此滞留区沿途氮的不断带人是河道下游氮含量升高的主要原因.

表 2 鄱阳湖水体的氮磷值

Tab.2 Concentrations of nitrogen and phosphorus in the water bodies of Lake Poyang

\begin{tabular}{|c|c|c|c|c|}
\hline 采样编号 & $\mathrm{NO}_{3}{ }^{-}-\mathrm{N}(\mathrm{mg} / \mathrm{L})$ & $\mathrm{NH}_{4}^{+}-\mathrm{N}(\mathrm{mg} / \mathrm{L})$ & $\mathrm{TN}(\mathrm{mg} / \mathrm{L})$ & $\mathrm{TP}(\mathrm{mg} / \mathrm{L})$ \\
\hline L2 & 0.86 & $*$ & 1.37 & 0.059 \\
\hline L4 & 0.88 & * & 1.12 & 0.060 \\
\hline L5 & 0.81 & * & 1.08 & 0.056 \\
\hline L6 & 0.79 & * & 0.91 & 0.052 \\
\hline L7 & 0.60 & $*$ & 0.89 & 0.036 \\
\hline L8 & 1.25 & 0.08 & 1.35 & 0.071 \\
\hline L9 & 1.29 & 0.15 & 未检测 & 0.057 \\
\hline L10 & 1.05 & 0.12 & 1.43 & 0.063 \\
\hline L11 & 1.13 & 0.17 & 1.32 & 0.067 \\
\hline $\mathrm{L} 12$ & 0.77 & $*$ & 1.44 & 0.061 \\
\hline L13 & 1.07 & 0.11 & 1.17 & 0.089 \\
\hline L14 & 0.76 & $*$ & 未检测 & 0.045 \\
\hline L15 & 0.84 & 0.08 & 1.03 & 0.080 \\
\hline L16 & 0.92 & 0.05 & 1.22 & 0.093 \\
\hline $\mathrm{L} 17$ & 1.05 & 0.12 & 1.24 & 0.138 \\
\hline L20 & 0.85 & $*$ & 1.12 & 0.031 \\
\hline L21 & 0.91 & * & 未检测 & 0.021 \\
\hline L22 & 0.83 & $*$ & 0.95 & 0.030 \\
\hline L24 & 0.91 & 0.11 & 1.00 & 0.083 \\
\hline L25 & 0.68 & $*$ & 未检测 & 0.054 \\
\hline L26 & 1.02 & 0.26 & 1.31 & 0.051 \\
\hline L27 & 1.00 & 0.18 & 1.25 & 0.130 \\
\hline L28 & 0.88 & 0.10 & 未检测 & 0.059 \\
\hline L29 & 0.71 & $*$ & 0.78 & 0.229 \\
\hline L30 & 0.46 & 0.08 & 1.10 & 0.073 \\
\hline L31 & 0.42 & 0.11 & 0.72 & 0.035 \\
\hline L32 & 0.45 & 0.04 & 0.63 & 0.031 \\
\hline L33 & 0.34 & $*$ & 0.53 & 0.035 \\
\hline L34 & 0.33 & 0.06 & 0.39 & 0.034 \\
\hline 均值 & $0.82 \pm 0.25$ & $0.10 \pm 0.06$ & $1.06 \pm 0.28$ & $0.067 \pm 0.042$ \\
\hline
\end{tabular}

*表示低于检测限.

湖体主河道下游 TP 含量分布比较均匀, 而在主湖区 L17、L27、L29 处 TP 含量非常高, 分别达到 $0.138 、 0.13 、 0.229 \mathrm{mg} / \mathrm{L}$, 主湖区 TP 含量较高的现象与 1983-1988 年期间研究得出的结果一致 ${ }^{[14]}$, 引起 此几处 TP 含量异常高的原因尚有待进一步研究.

2.3 鄱阳湖区农田水、城市污水及地下水的氮、磷特征

对农田水氮磷含量的分析结果表明(表 3), 农田水含有较高含量的 $\mathrm{TN}(13.47 \pm 18.07 \mathrm{mg} / \mathrm{L}$ )和 $\mathrm{TP}$ $(28.63 \pm 75.36 \mathrm{mg} / \mathrm{L})$. 样品采集于夏季, 正值晚稻插秧季节, 因此农田水中的高氮磷含量是有机氮肥(如农 家肥)和磷肥广泛施用的结果. 高含量的 $\mathrm{NO}_{3}{ }^{-}-\mathrm{N}(7.35 \pm 3.45 \mathrm{mg} / \mathrm{L})$ 和 $\mathrm{NH}_{4}{ }^{+}-\mathrm{N}(5.48 \pm 7.42 \mathrm{mg} / \mathrm{L})$ 分别出现在地 
下水和城市污水中. 这些高氮磷含量的农田水、城市废水以及地下水将对鄱阳湖流域河流乃至鄱阳湖水 体的氮磷负荷产生重要的影响.

表 3 鄱阳湖区农田水、城市污水及地下水氮磷含量

Tab.3 Nitrogen and phosphorus concentrations of different forms in agricultural drainage, groundwater and urban sewage in the Lake Poyang basin

\begin{tabular}{ccccc}
\hline & $\mathrm{NO}_{3}{ }^{-}-\mathrm{N}(\mathrm{mg} / \mathrm{L})$ & $\mathrm{NH}_{4}{ }^{+}-\mathrm{N}(\mathrm{mg} / \mathrm{L})$ & $\mathrm{TN}(\mathrm{mg} / \mathrm{L})$ & $\mathrm{TP}(\mathrm{mg} / \mathrm{L})$ \\
\hline 农田水 & $1.15 \pm 1.01$ & $0.90 \pm 0.67$ & $13.47 \pm 18.07$ & $28.63 \pm 75.36$ \\
城市污水 & $0.97 \pm 0.72$ & $5.48 \pm 7.42$ & $6.55 \pm 5.21$ & $1.15 \pm 1.44$ \\
地下水 & $7.35 \pm 3.45$ & $0.28 \pm 0.15$ & $7.80 \pm 3.70$ & $0.08 \pm 0.11$ \\
\hline
\end{tabular}

\section{4 鄱阳湖表底层氮、磷含量}

在鄱阳湖主湖区采集了水体表层及底层水样, 各采样点水深约 $10 \mathrm{~m}$ 左右. 鄱阳湖水体 $\mathrm{NO}_{3}{ }^{-}-\mathrm{N}$ 、 $\mathrm{NH}_{4}{ }^{+}-\mathrm{N} 、 \mathrm{TP}$ 的含量都是底层的偏高. 底层 $\mathrm{NO}_{3}{ }^{-}-\mathrm{N}$ 含量平均值为 $1.12 \pm 0.24 \mathrm{mg} / \mathrm{L}$, 而表层为 $0.91 \pm 0.11 \mathrm{mg} / \mathrm{L}$; TP 底层含量为 $0.13 \pm 0.07 \mathrm{mg} / \mathrm{L}$, 而表层为 $0.08 \pm 0.04 \mathrm{mg} / \mathrm{L}$ (图 2).
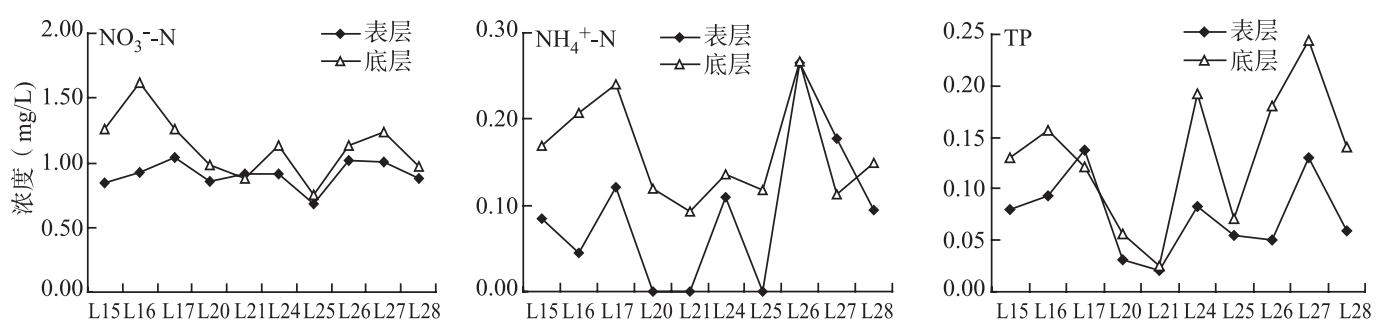

图 2 鄱阳湖表底层氮磷含量对比

Fig.2 The comparisom of nitrogen and phosphorus concentrations at the surface water and bottom water in Lake Poyang

\section{3 参考文献}

[1] Wang Baodong. Cultural eutrophication in the Changjiang (Yangtze River) plume: History and perspective. Estuarine, Coastal and Shelf Science, 2006, 69(3-4): 471-477.

[2] Chai Chao, Yu Zhiming, Song Xiuxian et al. The status and characteristics of eutrophication in the Yangtze River(Changjiang) estuary and the adjacent East China Sea, China. Hydrobiologia, 2006, 563(1): 313-328.

[3] 秦伯强. 长江中下游浅水湖泊富营养化发生机制与控制途径初探. 湖泊科学, 2002, 14(3): 193-202.

[4] 成小英, 李世杰. 长江中下游典型湖泊富营养化演变过程及其特征分析. 科学通报, 2006, 51(7): 848-855.

[5] 李博之. 鄱阳湖水体污染现状与水质预测, 规划研究. 长江流域资源与环境, 1996, 59(1): 60-66.

[6] 朱海虹, 张 本. 鄱阳湖 一 水文. 生物 - 沉积 - 湿地 - 开发整治. 合肥: 中国科学技术大学出版社, 1997: 125-128.

[7] 吕兰军. 鄱阳湖富营养化调查与评价. 湖泊科学, 1996, 8(3): 241-247.

[8] 吕兰军. 鄱阳湖富营养化评价. 水资源保护, 1994, (3): 47-52.

[9] 国家环境保护总局、《水和废水监测分析方法》编委会编. 水和废水监测分析方法(第四版). 北京: 中国环境科学出版社, 2002: 266-268.

[10] 王毛兰, 胡春华, 周文斌. 碱性过硫酸钾法测定水质总氮的影响因素. 光谱实验室, 2006, 23(5): 1046-1049.

[11] 江西省统计局编. 江西统计年鉴 2006. 北京: 中国统计出版社, 2006: 571 .

[12] 张维球. 解决用朝阳磷矿湿法生产过磷酸钙水分超标的问题. 磷肥与复肥, 2000, 15(1): 22-23.

[13] 秦伯强, 胡维平, 陈伟民等. 太湖梅梁湾水动力及相关过程的研究. 湖泊科学, 2000, 12(4): 327-333.

[14] 江西省科学院, 中国科学院南京地理湖泊研究所, 江西省山江湖开发治理委员会办公室主编. 鄱阳湖地图集. 北京: 科 学出版社, 1993: 17 . 